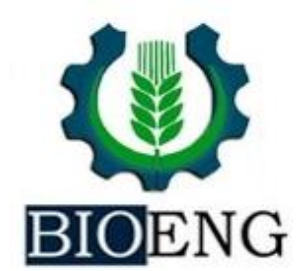

\title{
O PROCESSO DE INOVAÇÃO NA PRODUÇÃO DE LEITE DE BUBALINOS: UM ESTUDO DE CASO NO MUNICÍPIO DE QUEIROZ/SP
}

\author{
UNESP - Univ Estadual Paulista, Faculdade de Ciências e Engenharia, Tupã, SP, Brasil
}

Article history: Received 11 December 2017; Received in revised form 10 March 2018; Accepted 13 March 2018; Available online 27 March 2018.

\section{RESUMO}

A inovação vem se tornando primordial para pequenos produtores, visto que para se manterem no mercado atual é preciso aumentar a produtividade, melhorar a qualidade do produto ofertado e ter um bom sistema de gerenciamento de seu negócio. Desta forma, o objetivo do trabalho é analisar quais os tipos de inovações que uma comunidade produtora de leite de búfala do município de Queiroz/SP realiza e quais as forças restritivas e as forças propulsoras para a adoção de inovações. Para isto, foi utilizada uma abordagem qualitativa em que os produtores foram entrevistados através de uma pesquisa de campo. Como resultados, foram identificados que as inovações mais comuns entre os produtores são aquelas relacionadas a processo e organizacional. A influência familiar, o receio de financiamentos e outras atividades internas e externas à propriedade são fatores que restringem a adoção de inovação, enquanto que a proximidade entre os produtores e a perda do principal agente comprador de seus produtos são forças que impulsionam essa adoção. Percebeu-se, então, que para a comunidade avaliada a adoção de novas tecnologias é fundamental para que a mesma possa permanecer no mercado de leite de búfalas.

Palavras-chave: Adoção de inovação; Produção rural; Tecnologias produtivas.

\section{THE INNOVATION PROCESS IN BUBALINE MILK PRODUCTION: A CASE STUDY IN THE CITY OF QUEIROZ / SP}

\begin{abstract}
Innovation has become paramount for small producers, since in order to stay in the current market it is necessary to increase productivity, improve the quality of the product offered and have a good management system for your business. In this way, the objective of this work is to analyze the types of innovations that a buffalo milk producing community in the city of Queiroz / SP realizes and what are the restrictive forces and the driving force for adopting innovations. For this, a qualitative approach was used in which producers were interviewed through field research. As results, it was identified that the most common innovations among producers are those related to process and organizational. Family influence, fears of financing and other internal and external activities to the propriety are factors that restrict the adoption of innovation, while the proximity between producers and the loss of the main purchasing agent of yours products are forces that drive this adoption. It was then realized that for the evaluated community the adoption of new technologies is fundamental so that it can remain in the buffalo milk market.
\end{abstract}

Keywords: Adoption of innovation; Rural production; Productive technologies.

"nataliadadario@gmail.com 


\section{INTRODUÇÃO}

A bubalinocultura é uma atividade que vêm ganhando destaque no Brasil, devido à sua capacidade de trabalho animal, como também de produção de carne e leite (SANTINI et al., 2013). A potencialidade do segmento também se deve, segundo Veloso Junior (2011), pela taxa de conversão alimentar, fecundidade, adaptação climática, alta produtividade industrial, rusticidade, longevidade, docilidade, estacionalidade produtiva do animal, dentre outros aspectos.

Segundo o MAPA (2016), o rebanho brasileiro de búfalos é estimado em cerca de 1,15 milhão de bubalinos, sendo a região Norte a maior produtora do país, com 720 mil animais; em seguida aparece a região Nordeste, com 135 mil cabeças e depois a região Sudeste, com 104 mil cabeças. A Associação Brasileira dos Criadores de Búfalos (ABCB, 2016) estima um rebanho de três milhões de cabeça de bubalinos no Brasil. Esta discrepância entre dados se deve, muitas vezes, segundo Bernardes (2006), pelo fato dos dados serem subestimados, pois o registro de bubalinos se confunde com o de bovinos durante o cadastramento.

Apesar da região Norte ser a maior produtora de búfalos do Brasil, a sua produção é voltada para o mercado de produção de carne, diferente da região Sudeste, que privilegia a produção de leite (ANDRIGHETTO, 2011). Sturaro (2014) afirma que o fato da bubalinocultura estar voltada quase que completamente para a produção de leite na região Sudeste se deve ao mercado competitivo existente nessa região em relação ao queijo de leite de búfalas. De acordo com Teixeira et al. (2005), os derivados do leite de búfala, em especial a mozzarella e a ricota, são procurados não só por seu sabor característico, mas também por suas qualidades nutricionais, pois o leite de búfala possui elevado teor de proteínas e baixas quantidades de células somáticas, sendo que esta última, quando apresentada em altos valores, altera a composição do leite, comprometendo a qualidade de seus derivados (ANDRIGHETTO, 2011). Além destes fatores, este leite quando comparado ao leite de bovinos, possui um menor índice de colesterol, por isso vem ganhando destaque no mercado, dado o atributo relacionado a alimentação saudável.

Segundo a ABCB (2016), a tradicional mozzarella de búfala, um tipo de queijo fresco e um dos mais nobres do mundo, originário da Itália, no século XVI, só pode ser produzida exclusivamente com leite de búfalas. Por isto, existe um controle rigoroso para identificar a mozzarella de búfala verdadeira e proteger o consumidor. No Brasil, a ABCB criou o Selo de Pureza 100\% Búfalo para certificar as mozzarellas que são produzidas exclusivamente por leite de búfalas.

$\mathrm{O}$ grande problema da produção de mozzarella de búfala, conforme Olivieri (2004), é que no período de entressafra (primavera/verão) o processamento deste queijo sofre uma queda, devido à sazonalidade reprodutiva dos animais. Segundo Andrighetto (2011), para que a estacionalidade de produção seja minimizada, deve-se investir em técnicas de manejo que visem a maior homogeneidade na distribuição de partos.

Além do problema da sazonalidade na produção de leite de búfala que afeta a produção dos derivados, para comercializar estes produtos no mercado externo faz-se necessário melhorar a qualidade do leite. Para isto deve-se investir em inovação, que na perspectiva de Rogers (1983) pode significar uma ideia, uma prática ou objeto em si que é percebido como novo por um indivíduo ou outra unidade de adoção (ROGERS, 1983). Na pecuária bubalina envolveria melhorias ou o uso de: melhoramento genético da espécie com o uso da biotecnologia e multiplicação destes com a inseminação artificial; equipamentos, como de irrigação, que garantam que em épocas de seca o pasto continue crescendo para garantir uma boa nutrição dos animais e, consequentemente, boa produção de leite; equipamentos para 
acompanhamento da gestação, como ultrassons; dentre outras técnicas de manejo. Segundo Gonçalves (2008), nos meses entre novembro e fevereiro as búfalas não produzem leite devido a característica de sazonalidade reprodutiva em monta natural, sendo necessário o emprego de tecnologia, como a inseminação artificial, de modo a uniformizar a oferta de carne e leite durante o ano todo.

Apesar das contribuições que já existem de inovação para o setor da pecuária, existem produtores que possuem certa resistência em adotar algum tipo de inovação. A decisão de adoção de inovação é concebida na teoria de difusão de inovação, na qual envolve a inovação em si e os canais pelos quais a mesma é comunicada ao longo do tempo entre os membros de um sistema social (ROGERS, 1983). Para Martins (2015), entende-se por adoção de inovação tecnológica a adoção de novas tecnologias, como dispositivos e máquinas, que possam aumentar a competitividade (MARTINS, 2015). Souza Filho (2011) também cita quatro fatores que podem influenciar na adoção de inovações no setor do agronegócio: características socioeconômicas e condição do produtor; características da produção e da propriedade rural; características da tecnologia e fatores sistêmicos.

Pressupõe-se que algumas características citadas pelo autor influenciam na adoção de inovações na produção de leite de búfala de uma comunidade do município de Queiroz,

\section{CONTRIBUIÇÕES TEÓRICAS}

\section{Inovação}

Com o passar dos anos, o homem vem buscando elevar cada vez mais sua produtividade, com base no sistema capitalista implementado no mundo todo (VERTEL et al., 2013). Para enfrentar este desafio atual e se manter no mercado, os produtores, segundo Cirani e Moraes (2010), veem-se obrigados a aumentar sua produtividade, melhorar sempre em seus produtos e métodos de gestão, e aliado a localizado na região da Nova Alta Paulista (SP).

Assim, o objetivo deste trabalho foi o de analisar quais os tipos de inovações que esta comunidade possui e quais as forças restritivas e as forças propulsoras para a adoção de inovações. Delimitou-se o estudo em uma comunidade produtora de leite de búfala do município de Queiroz/SP, visto que a produção neste município é um dos destaques no estado de São Paulo, em termos de rebanho efetivo, que conforme o IBGE (2016) apresentou no ano de 2015, um total de 1.406 cabeças.

$\mathrm{O}$ tema a ser estudado justifica-se pela importância que a inovação possui no agronegócio nacional, visto que sua adoção possibilita aumento de produtividade e melhora na qualidade do produto, além de auxiliar na gestão do negócio, seja em relação a recursos financeiros, humanos ou até mesmo, ambientais.

O trabalho foi estruturado em cinco seções, de modo que após esta introdução, na segunda seção são apresentadas as contribuições teóricas acerca de inovação e das variáveis que influenciam no processo de adoção de inovação. Na terceira seção é descrita a metodologia de pesquisa utilizada. A quarta seção traz os resultados e discussões do trabalho, organizado em caracterização dos produtores, inovações realizadas pelos mesmos e forças restritivas e propulsoras no processo de adoção de inovação do grupo em questão. A quinta e última seção traz algumas considerações finais, com base nas análises realizadas.

tudo isto, manter a preservação do meio ambiente.

Para conseguir alcançar este grande desafio de alinhar todos estes requisitos, é necessário o desenvolvimento de inovações para a incorporação de tecnologias. Conforme Hage (1999), a partir da inovação é possível o desenvolvimento de equipamentos e 
produtos que deem suporte à concorrência entre os povos.

$\mathrm{Na}$ perspectiva de Schumpeter (1984), o caráter evolutivo do sistema econômico não é explicado pelo aumento da população e do capital, ou pelas variações do sistema monetário, mas sim, pela introdução de inovações. Para esse autor, o impulso fundamental que põe e mantém em funcionamento a máquina capitalista provem dos novos bens de consumo, dos novos métodos de produção ou transporte, dos novos mercados e das novas formas de organização industrial criadas pela empresa capitalista; todas essas transformações seriam partes do processo de mutação industrial, que revoluciona a estrutura econômica a partir de dentro, destruindo incessantemente o antigo e criando elementos novos (SCHUMPETER, 1984).

$$
\text { A OECD (2005) conseguiu }
$$
centralizá-las em quatro categorias: (a) inovação de produto, (b) inovação de processo, (c) inovação de marketing e (d) inovação organizacional, conforme apresentado na Tabela 1.

Tabela 1. Tipos de Inovação

\begin{tabular}{c|l}
\hline Tipos de Inovação & \multicolumn{1}{c}{ Características } \\
\hline Inovação de Produto & $\begin{array}{l}\text { Representada pela inserção de um produto novo ou de um } \\
\text { produto melhorado, respeitando as suas características e } \\
\text { funcionalidades. Pode-se incluir em inovações de produto as } \\
\text { melhorias nas especificações técnicas, nos componentes e } \\
\text { materiais ou no software utilizado. }\end{array}$ \\
\hline Inovação de Processo & $\begin{array}{l}\text { Representa a adoção de um método de produção ou } \\
\text { distribuição novo ou significativamente melhorado, podendo } \\
\text { incluir mudanças significativas de métodos, tecnologia, } \\
\text { equipamentos, softwares e de organização da produção. }\end{array}$ \\
\hline Inovação de Marketing & $\begin{array}{l}\text { Consiste na elaboração de novas metodologias de marketing. } \\
\text { Pode envolver: melhorias no design do produto ou da } \\
\text { embalagem, no preço, na distribuição ou ainda na promoção } \\
\text { do mesmo. O que distingue a inovação de marketing das } \\
\text { outras inovações é a efetivação de um novo conceito ou de } \\
\text { uma nova estratégia que substitua a metodologia utilizada } \\
\text { outrora. }\end{array}$ \\
\hline Inovação & $\begin{array}{l}\text { Fundamenta-se na instalação de um novo método } \\
\text { organizacional nos padrões da organização ou nas relações } \\
\text { externas. Esta inovação auxilia no desempenho da empresa, } \\
\text { pois reduz custos administrativos ou de transações, melhora } \\
\text { as condições de trabalho e, consequentemente a } \\
\text { produtividade e incentiva a capacidade de aprendizado. }\end{array}$ \\
\hline
\end{tabular}

Fonte: Adaptado de OECD (2005).

Para Cunha et al. (2011), o setor do agronegócio, através da inovação, vem se desenvolvendo ao longo do tempo. Em um primeiro momento, com a $1^{\mathrm{a}}$ Revolução Agrícola, a agricultura se aproximou da pecuária por meio da tração animal. Em seguida, a $2^{\mathrm{a}}$ Revolução Agrícola trouxe o uso de fertilizantes químicos com o intuito de melhorar a produção rural. Apesar dos movimentos contrários em todo o mundo desta agressão ecológica, a agricultura caminhou para a Revolução Verde, onde as práticas tecnológicas (variedades geneticamente melhoradas, fertilizantes químicos, agrotóxicos, irrigação e motomecanização) vieram para viabilizar a monocultura. O agronegócio já está na era da $3^{\mathrm{a}}$ Revolução Agrícola, em que a biotecnologia ganha espaço para 0 desenvolvimento de sementes modificadas geneticamente, a fim de garantir condições de competitividade internacional de todos 
os produtos, e isso acarreta em melhorias genéticas nos animais.

Segundo Buainain (2014), no modelo atual o foco está nos capitais, como infraestrutura, máquinas, tecnologia e qualidade da terra. A inovação no campo com o auxílio da tecnologia busca a eficiência do uso do solo: produzir mais, utilizando menos.

\section{Variáveis que influenciam no processo de adoção de inovação}

Neumann (2013) destaca que as organizações operam de forma competitiva num ambiente complexo sujeito às modificações contínuas de mercado. Os fatores humanos e econômicos são particularmente importantes, seja na análise do ambiente ou na geração de ideias que levem a viabilidade do negócio. Para isso, a inovação deve inter-relacionar as necessidades dos clientes, a produtividade e competitividade, os serviços ou modelos comerciais, e o desenvolvimento de novos produtos.

Flexibilizar o conhecimento demonstra ser uma etapa importante num processo de inovação. Robbins (2005), fundamentando-se na teoria de Kurt Lewin, afirma que na mudança no comportamento de um indivíduo deve haver um processo de descongelamento/recongelamento de ideias, em que o conhecimento aprendido, por meio de novas práticas exercitadas, possibilite que o sujeito abandone as antigas ideias e passe a incorporar as novas.

Ainda segundo o mesmo autor, durante o processo de descongelamento existem forças restritivas e forças propulsoras que levam o indivíduo ao estado desejado, conforme apresentado na Figura 1.

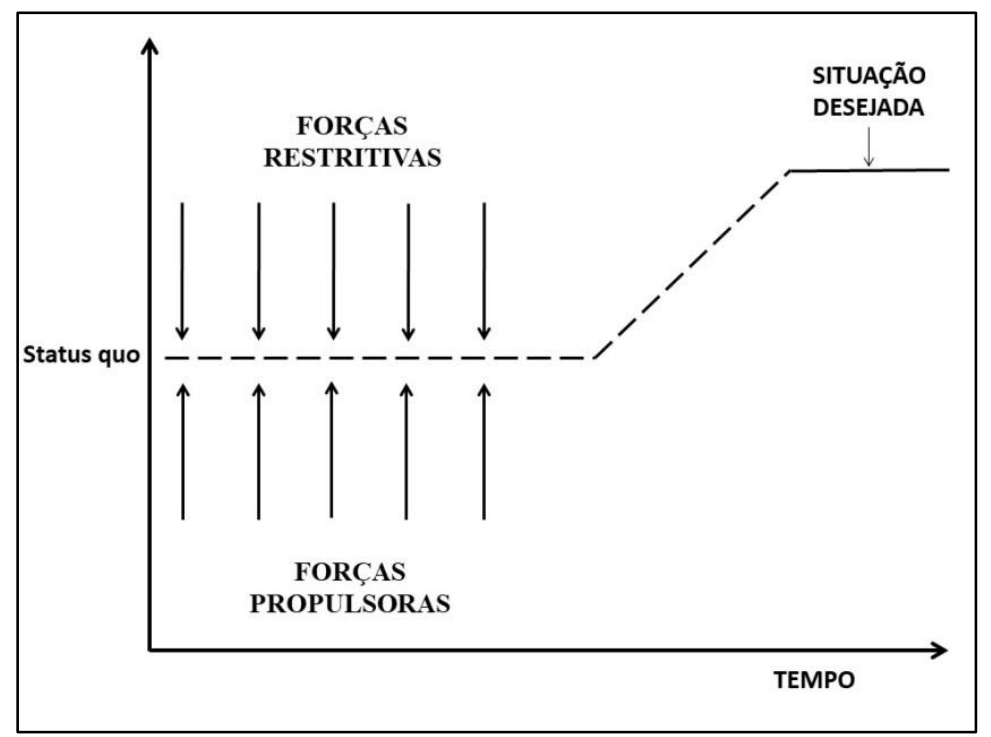

Figura 1. Descongelando o status quo. Fonte: Robbins (2005).

Segundo Robbins (2005), as forças restritivas são aquelas que impedem o movimento no sentido da mudança, enquanto as forças propulsoras remetem a quebra de paradigmas e, consequentemente, impulsionam o comportamento na direção pró-mudança.

A identificação das variáveis representa uma etapa importante na análise das forças que impulsionam ou que restringem uma inovação. Essa caracterização é recorrente nas pesquisas realizadas em diferentes setores. A propósito, no estudo de Cirani e Moraes $(2010)^{2}$ são evidenciadas variáveis que os autores consideraram como determinantes à inovação na indústria sucroalcooleira.

\footnotetext{
${ }^{2}$ As variáveis trabalhadas pelos autores, a partir da literatura econômica, são: origem do capital, se nacional ou estrangeiro; orientação exportadora; grupo - se participa de grupo empresarial; tipo de gestão da organização (profissional ou familiar); área total explorada; percentual de capital próprio da empresa; associação.
} 
Dentre as variáveis apresentadas, diversas possuem ressonância em atividades da produção agropecuária. Diante de tal nível de pertinência, o presente estudo adaptou algumas dessas variáveis de análise à inovação:

a) Origem da renda familiar - esta variável indica se a renda familiar é proveniente, exclusivamente, da propriedade ou não. Pressupõe-se que produtores que tenham uma atividade econômica fora da propriedade tenderiam a investir menos em sua propriedade, consequentemente, investiriam menos em tecnologia;

b) Motivo pela produção de bubalinos - o objetivo desta variável seria verificar o porquê que os produtores optam por este tipo de produção. Presume-se que produtores que optaram por esta produção, tendo em vista a oportunidade do mercado, tenham maiores chances de adotar tecnologia do que aqueles que tenham sofrido uma influência familiar. Barth et al (2016) também sinalizam que a falta de avanços tecnológicos na agricultura de pequeno porte, a expansão das indústrias para o ambiente rural e os melhores acessos à educação e transporte, permitiram novas oportunidades para os jovens, garantindo renda e tornando-os mais independentes, assumindo, assim, um maior interesse em permanecer no campo;

c) Tempo no mercado - acredita-se que esta variável influencie muito no

\section{MATERIAL E MÉTODO}

O estudo possui uma natureza aplicada, pois objetiva-se gerar conhecimentos dirigidos à solução de problemas específicos para aplicações práticas e apresenta uma abordagem qualitativa, pois busca compreender $\mathrm{o}$ fenômeno estudado e interpretar os aspectos profundos do comportamento humano, por meio de procedimentos de cunho racional e intuitivo (MARCONI; LAKATOS, 2003).

A pesquisa possui objetivo descritivo, uma vez que pretende retratar as características de certa população, processo de adoção de uma tecnologia, pois se supõe que quanto maior o tempo neste segmento, menor seja o interesse em inovar (pois maior seria a resistência);

d) Produtividade - espera-se que quanto maior for a produtividade, maior será a tendência do produtor a inserir tecnologia em sua produção, pois o conjunto de equipamentos poderia ser utilizado com um maior número de bubalinos, assim, o custo unitário ficaria reduzido para maiores produtividades;

e) Associação - esta variável indica se o produtor participa ou não de associações do setor. No caso do produtor participar de associações faria com que o mesmo tivesse um maior contato com pessoas do segmento e técnicos especializados. Consequentemente, maior seria seu contato com as novas tecnologias e maior seria a tendência a adotá-las. Tal análise também é amparada por Souza Filho et al. (2011);

f) Capital próprio - esta variável indica se os produtores possuem recursos próprios ou se necessitam de fontes de financiamento. Pois $\mathrm{o}$ fato do produtor possuir recursos próprios o faria enfrentar maiores riscos, portanto, maior seria o investimento em tecnologias. Segundo Rover (2011), a autonomia também é um fator fundamental para o processo de inovação, pois o autor afirma que a capacidade de criação e inovação está relacionada ao seu grau de liberdade.

envolvendo técnicas de coleta de dados (GIL, 2002).

Com relação aos procedimentos técnicos, o método utilizado foi a pesquisa de campo, cuja técnica aplicada para a obtenção dos dados foi $o$ uso de questionários semiestruturados, pois contou com questões predefinidas, porém, no decorrer da entrevista foi possível acrescentar outras questões inerentes ao estudo.

A pesquisa foi realizada em outubro de 2016 no município de Queiroz/SP, sendo realizado um estudo de caso com um 
grupo informal de sete pequenos produtores de leite de búfala. Devido ao fato deste grupo ser pequeno, não foi necessário determinar um tamanho amostral, pois todos os produtores pertencentes a este grupo responderam à entrevista.

Os questionários foram aplicados a fim de (a) verificar se há algum tipo de inovação na produção agropecuária bubalina (de produto, de processo, de marketing ou organizacional) no período de 2013 a 2016, de acordo com a classificação da OECD (2005); (b) averiguar quais são as influências positivas para a adoção de uma inovação; (c) constatar quais são as dificuldades desta comunidade para a implementação de

\section{RESULTADOS E DISCUSSÃO}

\section{Caracterização do objeto de estudo}

A produção de leite de búfala no município de Queiroz/SP se desenvolveu quando uma queijaria se instalou na região em meados da década de 1990. Pequenos proprietários de terra daquela região viram tecnologia. A partir destas respostas, resguardando-se o nome ou quaisquer informações dos indivíduos que os identificassem, foi possível analisar os tipos de inovações e as forças restritivas e as propulsoras no processo de inovação desta comunidade.

As variáveis analisadas para verificar a influência no processo de adoção de inovação da comunidade em questão foram adaptadas da metodologia de Cirani e Moraes (2010). Para esta pesquisa considerou-se as seguintes variáveis: (a) origem da renda familiar, (b) motivo pela produção de bubalinos, (c) tempo no mercado, (d) produtividade, (e) associação e (f) capital próprio.

neste negócio uma oportunidade para criação de búfalo, pois este mercado ainda encontrava-se em formação.

Atualmente este município possui destaque no estado de São Paulo, em termos de rebanho efetivo (ver Figura 2).

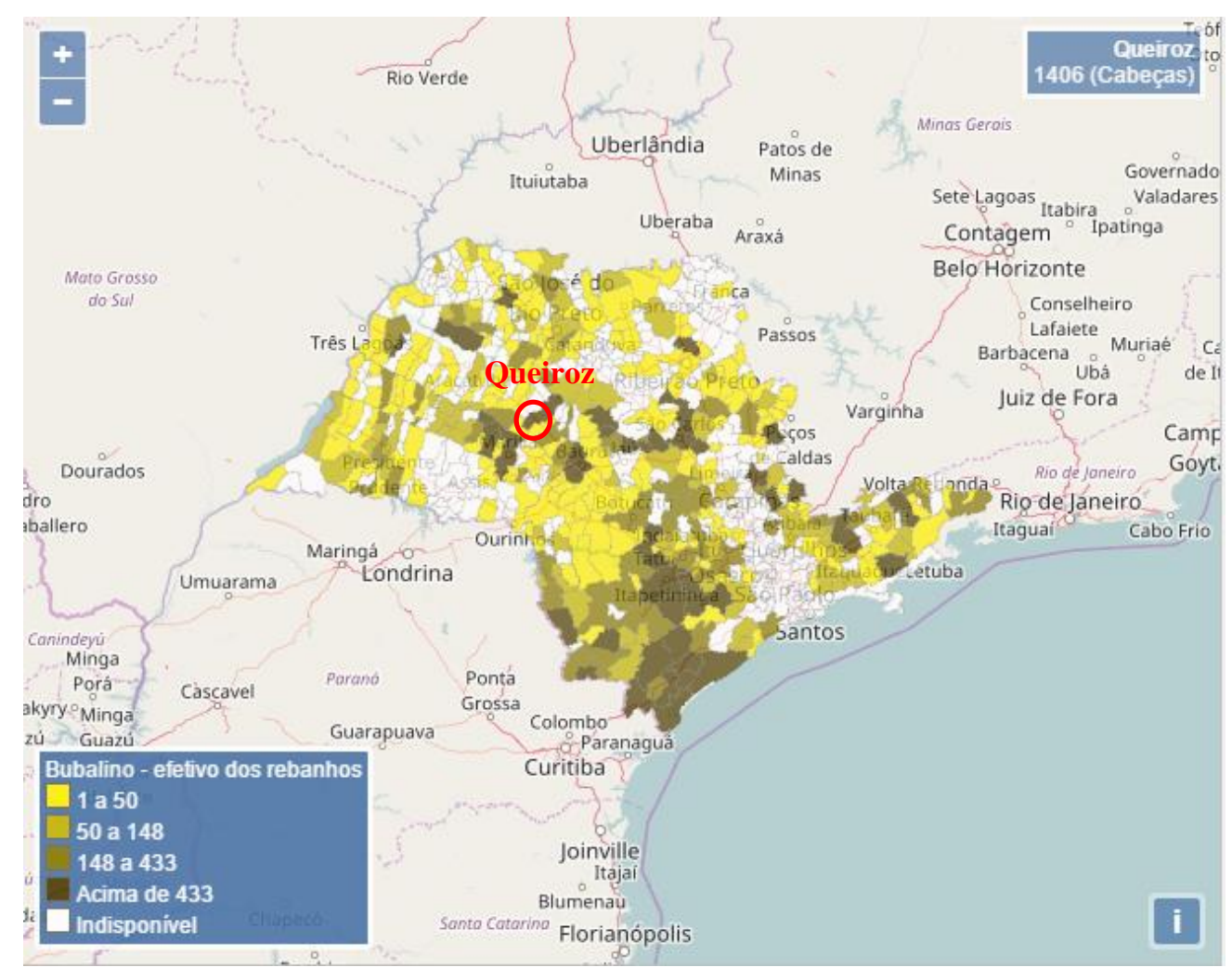

Figura 2. Efetivo de rebanhos bubalinos no estado de São Paulo no ano de 2015.

Fonte: IBGE (2016). 
Pela Figura 2, pode-se perceber que na mesma região os municípios de Pompéia e Marília também são destaques na produção de búfalos. Entretanto, quando comparado o número de cabeças de bubalinos pela área do munícipio, nota-se que o município de Queiroz possui a maior densidade de animais por quilômetro quadrado, segundo consta na Tabela 2 .

Tabela 2. Municípios destaque em rebanhos de bubalinos na região de Queiroz

\begin{tabular}{cccc}
\hline Município & $\begin{array}{c}\text { Número de } \\
\text { Cabeças de } \\
\text { búfalos }\end{array}$ & Área $\left.\mathbf{( k m}^{2}\right)$ & $\begin{array}{c}\text { Densidade } \\
\text { (número de } \\
\text { cabeças/km² }\end{array}$ \\
\hline Marília & 1.354 & $1.170,515$ & 1,15 \\
Pompéia & 2.136 & 784,674 & 2,72 \\
Queiroz & 1.406 & 234,914 & 5,98 \\
\hline
\end{tabular}

Fonte: Adaptado de IBGE (2016).

A característica comum dos produtores do município de Queiroz é o fato destes proprietários formarem um grupo informal, que segundo Robbins (2005), este tipo de grupo possui formação natural que surge em resposta à necessidade de contato social. Ainda segundo o mesmo autor, esta formação pode-se dar pelo fato de seus membros apresentarem características em comum, definidos como grupos de amizade, ou pelo fato de se reunirem para atingir um objetivo comum, os chamados grupos de interesse. No caso desta comunidade este grupo foi formado por ambos os fatores, pois além da afinidade por possuírem características comuns, eles estão sempre em contato a fim de atingir o mesmo objetivo: a produção de leite de bubalinos.

Tendo em vista o fechamento da queijaria, em setembro de 2016, que demandava o leite destes produtores, os mesmos vêm buscando a comercialização de seus produtos com um laticínio da região do Vale do Ribeira (estado de São Paulo). Entretanto, para que esta negociação aconteça, os produtores deverão se adaptar às exigências deste comprador. Estas exigências recaem sobre os fatores que melhoram a qualidade do leite oferecido.

A exigência de uma melhor qualidade do leite, segundo informações dos próprios produtores, vem pelo fato deste laticínio da Região do Vale do Ribeira buscar a exportação de seus queijos para a Itália, visto que a demanda neste país é muito elevada. Para isto, será necessário melhorar toda a cadeia produtiva dos queijos, para que assim, consiga-se atingir todos os requisitos exigidos pelo país importador.

No Brasil, a ABCB criou o Selo de Pureza $100 \%$ Búfalo para identificar a mozzarella de búfala verdadeira e proteger o consumidor, pois o produto é alvo de constantes falsificações (ABCB, 2016). O selo de Pureza ABCB, de acordo com o Regulamento Técnico do Programa do Selo de Pureza ABCB, significa a garantia da transparência de informações ao consumidor, a fim de evitar a concorrência desleal mercadológica. Para a certificação do selo em questão, uma amostra é selecionada e encaminhada para um laboratório credenciado, a fim de avaliar a conformidade dos resultados da amostra em relação às especificações da Norma Técnica do Programa Selo de Pureza. Caso os resultados obtidos se enquadrem nas especificações da Norma Técnica, será concedido a Certificação (ABCB, 2014).

Segundo os produtores, devido à possibilidade de 'futura' comercialização entre a comunidade em questão e o laticínio da região do Vale do Ribeira, auditorias e vistorias pelo agente comprador serão realizadas no local, a fim de garantir o controle e a permanência da qualidade do leite, atendendo às exigências do Selo de Pureza 100\% Búfalo que o laticínio já possui. 
Inovações realizadas pelos produtores

Por meio das respostas dos questionários foi possível verificar as inovações que cada produtor adquiriu, conforme representado pela Tabela 3 .

Com base na Tabela 3, pode-se verificar que as inovações mais comuns a todos os produtores foram as relacionadas a processo e organizacional, sendo destaque a identificação do bubalino por meio de brincos, o uso do tanque de refrigeração e a utilização da ordenha mecânica, com exceção somente de um produtor $\left(\mathrm{X}_{5}\right)$.

Tabela 3. Inovações realizadas pelos produtores de leite de búfala

\begin{tabular}{|c|c|c|c|c|}
\hline \multirow{2}{*}{$\begin{array}{c}\text { Produto } \\
\mathbf{r}\end{array}$} & \multicolumn{4}{|c|}{ Tipos de Inovação } \\
\hline & Produto & Processo & $\begin{array}{l}\text { Marketi } \\
\text { ng }\end{array}$ & $\begin{array}{c}\text { Organizacion } \\
\text { al }\end{array}$ \\
\hline \multirow{6}{*}{$\mathbf{X}_{1}$} & \multirow{6}{*}{-} & $\begin{array}{l}\text { Complementação da } \\
\text { alimentação }\end{array}$ & \multirow{6}{*}{ - } & \multirow{6}{*}{$\begin{array}{l}\text { Identificação } \\
\text { do bubalino }\end{array}$} \\
\hline & & Tanque de Refrigeração & & \\
\hline & & Ordenha Mecânica & & \\
\hline & & Ordenha Canalizada & & \\
\hline & & $\begin{array}{l}\text { Rotacionamento das } \\
\text { Pastagens }\end{array}$ & & \\
\hline & & Identificação do bubalino & & \\
\hline \multirow{7}{*}{$\mathbf{X}_{2}$} & \multirow[t]{2}{*}{ - } & $\begin{array}{l}\text { Complementação da } \\
\text { alimentação }\end{array}$ & \multirow{7}{*}{$\begin{array}{l}\text { Rotulage } \\
\text { m dos } \\
\text { derivado } \\
\text { s }\end{array}$} & \multirow{3}{*}{$\begin{array}{l}\text { Identificação } \\
\text { do bubalino }\end{array}$} \\
\hline & & Tanque de Refrigeração & & \\
\hline & \multirow[b]{2}{*}{$\begin{array}{c}\text { Produção de } \\
\text { derivados }\end{array}$} & Ordenha Mecânica & & \\
\hline & & $\begin{array}{l}\text { Rotacionamento das } \\
\text { Pastagens }\end{array}$ & & \multirow{4}{*}{$\begin{array}{l}\text { Controle da } \\
\text { reprodução }\end{array}$} \\
\hline & \multirow{3}{*}{$\begin{array}{c}\text { Uso de } \\
\text { matéria-prima } \\
\text { importada nos } \\
\text { derivados }\end{array}$} & Irrigação & & \\
\hline & & $\begin{array}{c}\text { Aquisição de equipamentos } \\
\text { (fabricação dos derivados) }\end{array}$ & & \\
\hline & & Identificação do bubalino & & \\
\hline \multirow{5}{*}{$\mathbf{X}_{3}$} & \multirow{5}{*}{-} & $\begin{array}{l}\text { Complementação da } \\
\text { alimentação }\end{array}$ & \multirow{5}{*}{-} & \multirow{5}{*}{$\begin{array}{c}\text { Identificação } \\
\text { do bubalino }\end{array}$} \\
\hline & & Tanque de Refrigeração & & \\
\hline & & Ordenha Mecânica & & \\
\hline & & $\begin{array}{l}\text { Rotacionamento das } \\
\text { Pastagens }\end{array}$ & & \\
\hline & & Identificação do bubalino & & \\
\hline \multirow{3}{*}{$\mathbf{X}_{4}$} & \multirow{3}{*}{-} & Tanque de Refrigeração & \multirow{3}{*}{ - } & \multirow{3}{*}{$\begin{array}{l}\text { Identificação } \\
\text { do bubalino }\end{array}$} \\
\hline & & Ordenha Mecânica & & \\
\hline & & Identificação do bubalino & & \\
\hline \multirow{2}{*}{$\mathbf{X}_{5}$} & \multirow{2}{*}{ - } & Tanque de Refrigeração & \multirow[b]{2}{*}{-} & \multirow{2}{*}{$\begin{array}{c}\text { Identificação } \\
\text { do bubalino }\end{array}$} \\
\hline & & Identificação do bubalino & & \\
\hline \multirow{3}{*}{$\mathbf{X}_{6}$} & \multirow{3}{*}{-} & Tanque de Refrigeração & \multirow{3}{*}{ - } & \multirow{3}{*}{$\begin{array}{c}\text { Identificação } \\
\text { do bubalino }\end{array}$} \\
\hline & & Ordenha Mecânica & & \\
\hline & & Identificação do bubalino & & \\
\hline \multirow{3}{*}{$\mathbf{X}_{7}$} & \multirow{3}{*}{-} & Tanque de Refrigeração & & \\
\hline & & Ordenha Mecânica & - & Identificaçao \\
\hline & & Identificação do bubalino & & do bubalıno \\
\hline
\end{tabular}

Fonte: elaborado pelos autores 
Apesar da identificação de bubalinos por meio de brincos, assim como em bovinos, apresentar algumas desvantagens, como leitura somente à pequena distância, desaparecimento por meio de retirada de outro animal, enfraquecimento por ação do sol, chuva e lama, dentre outras desvantagens, segundo Lopes (1997) esta técnica ainda se apresenta como um dos sistemas tradicionais mais utilizados que resultam em uma identificação prática de cada animal do rebanho, pois é uma alternativa simples e economicamente viável, sendo a utilização de dois brincos com o mesmo número uma alternativa para os inconvenientes deste instrumento.

Além disto, a utilização deste recurso é importante para a rastreabilidade do SISBOV (Serviço Brasileiro de Rastreabilidade da Cadeia Produtiva de Bovinos e Bubalinos), sendo este, um serviço que tem como objetivo, segundo o MAPA (2017), possibilitar o rastreamento do rebanho bubalino e bovino, do nascimento ao abate, por meio do registro e identificação destes animais em todo o país a fim de disponibilizar relatórios de qualidade do rebanho para propiciar apoio à tomada de decisão (MAPA, 2017). Ainda que o uso de brincos seja adotado por quase todos os produtores, esta técnica só é utilizada para controle interno da propriedade, sendo que as informações coletadas não são passadas à frente na hora da comercialização do leite.

Outra técnica importante que os produtores levaram em consideração é o manejo de ordenha que, segundo Andrighetto (2011), garante a qualidade do leite de búfala microbiologicamente. A ordenha mecânica, quando realizada com rigorosa higiene, permite manter a qualidade do leite. Associada a esta técnica, possuir um tanque de refrigeração impede que organismos patogênicos modifiquem as características do produto e consequentemente sua qualidade.

Outra conclusão que se pode verificar com base na Tabela acima foi o fato dos produtores $\mathrm{X}_{1}, \mathrm{X}_{2}$ e $\mathrm{X}_{3}$ serem os que mais adotaram inovações em suas produções. $\mathrm{O}$ produtor $\mathrm{X}_{5}$ foi o que menos adotou tecnologias, fato este que será melhor analisado na próxima seção.

\section{Forças restritivas e propulsoras no processo de inovação}

Levando-se em conta os parâmetros apresentados por Robbins (2005) fundamentados na teoria de Kurt Lewin, este tópico interrelaciona as variáveis propostas e o processo de adoção de inovação.

Com relação à origem da renda familiar, a maioria dos produtores obtêm suas rendas a partir da própria propriedade, com exceção do produtor $\mathrm{X}_{5}$, que também obtém renda com outra atividade externa à propriedade. Devido ao produtor $\mathrm{X}_{5}$ ter outra fonte de renda fora da propriedade, do mesmo ser o que menos inova e ser o único que não tem a pretensão de adquirir novas tecnologias futuramente, leva a inferir que produtores que se sustentam exclusivamente da renda proveniente de atividades ligadas à propriedade possuem uma maior probabilidade de adoção de inovações. É importante destacar também que outra situação que vem ocorrendo dentre os produtores que investem em menor número de inovações $\left(\mathrm{X}_{4}, \mathrm{X}_{5}\right.$ e $\left.\mathrm{X}_{7}\right)$ é que os mesmos estão utilizando suas terras para a plantação de culturas (amendoim, batata e milho) e arrendando parte de sua terra para a produção de canade-açúcar, devido à proximidade destas propriedades com uma indústria sucroalcooleira. Este último fator também pode ser uma condição restritiva para que os proprietários parem de investir em inovação para a produção de leite de búfala.

Acerca da motivação pela produção de bubalinos, somente os produtores $\mathrm{X}_{1} \mathrm{e}$ $\mathrm{X}_{2}$ não tiveram influência familiar, os demais foram influenciados pela família que já praticavam este tipo de produção. Dessa forma, nota-se que estes produtores viram este segmento como oportunidade, o que faz com que invistam cada dia mais em tecnologias para melhorar sua produtividade.

A variável tempo de mercado não foi relevante nesta análise, pois acreditava-se 
que quanto maior o tempo neste segmento maior seria a resistência em investir em inovação, entretanto, $\mathrm{o}$ produtor $\mathrm{X}_{1}$, destaque na adoção de tecnologia, contrapôs a concepção inicial, pois $\mathrm{o}$ mesmo possui mais de vinte anos neste ramo. No entanto, não se pode concluir que o contrário aconteça (maior o tempo de mercado, maior a propensão em aderir tecnologia), pois o produtor $\mathrm{X}_{2}$ também foi destaque na aquisição de tecnologia e está neste ramo somente há seis anos. É necessário ressaltar que fatores educacionais e culturais também possam influenciar nesta adoção de inovações, em encontro às ideias de Souza Filho et al. (2011).

No tocante à produtividade, não se pode concluir que o mesmo tenha influência sobre estes produtores, uma vez que os maiores produtores de leite avaliados $\left(\mathrm{X}_{1}, \mathrm{X}_{4}\right.$ e $\left.\mathrm{X}_{7}\right)$ demonstraram respostas diferentes para a implementação de inovações.

Em relação à variável associação, nenhum dos produtores avaliados participa de associações do segmento. Portanto, não se pode generalizar se este fator influenciaria ou não na aquisição de tecnologia. Entretanto, indícios mostram que os produtores que possuem uma maior proximidade $\left(\mathrm{X}_{1}, \mathrm{X}_{2}\right.$ e $\left.\mathrm{X}_{3}\right)$ dentre os outros do grupo, possuem uma tendência maior a adquirir a tecnologia que o outro já tenha implementado. Portanto, o conceito de isomorfismo proposto por DiMaggio e Powell (1983), em que uma unidade (indivíduo) tende a adotar processos e estruturas semelhantes às demais unidades (indivíduos), pode ser aplicado como uma força propulsora no processo de inovação.

Com respeito à variável capital próprio, a mesma não se mostrou relevante para a análise em questão, pois todos os produtores possuem capital próprio.
Entretanto, outro fator que se mostrou interessante, foi que os produtores que não possuem renda para aderir a uma tecnologia possuem certa resistência a financiamentos. Isso demonstra que eles acreditam ser incerto o retorno da inovação, visto que não é tão relevante a ponto de assumir uma dívida em um financiamento, podendo ser considerado arriscado tal retorno.

A possibilidade de inovação requer uma análise detalhada da situação atual, o denominado status quo. O percurso para o atingimento da situação desejada, ou inovação, é influenciada por dois fatores: as forças restritivas e propulsoras. Entende-se como forças restritivas tudo aquilo que dificulta uma inovação. Em contrário estariam as forças propulsoras, que são representadas pelas variáveis facilitadoras. Um profundo estudo dessas forças permite gerar um prognóstico do tempo necessário para a implantação de uma inovação.

A partir das análises realizadas acima, pode-se condensar as informações na Figura 3.

Nesta Figura foi possível verificar que existe uma tendência em que produtores que possuem atividades profissionais fora da propriedade ou mesmo aqueles que possuem outras atividades econômicas dentro da propriedade, tendem a ter restrições quanto a adoção de inovações. Além destes fatores, a influência familiar e a aversão a riscos de financiamentos também são forças restritivas deste processo. De maneira oposta, existem forças que impulsionam a adoção de inovações, dentre as analisadas pode-se citar a proximidade entre os produtores e a perda do maior agente consumidor de seus produtos. 


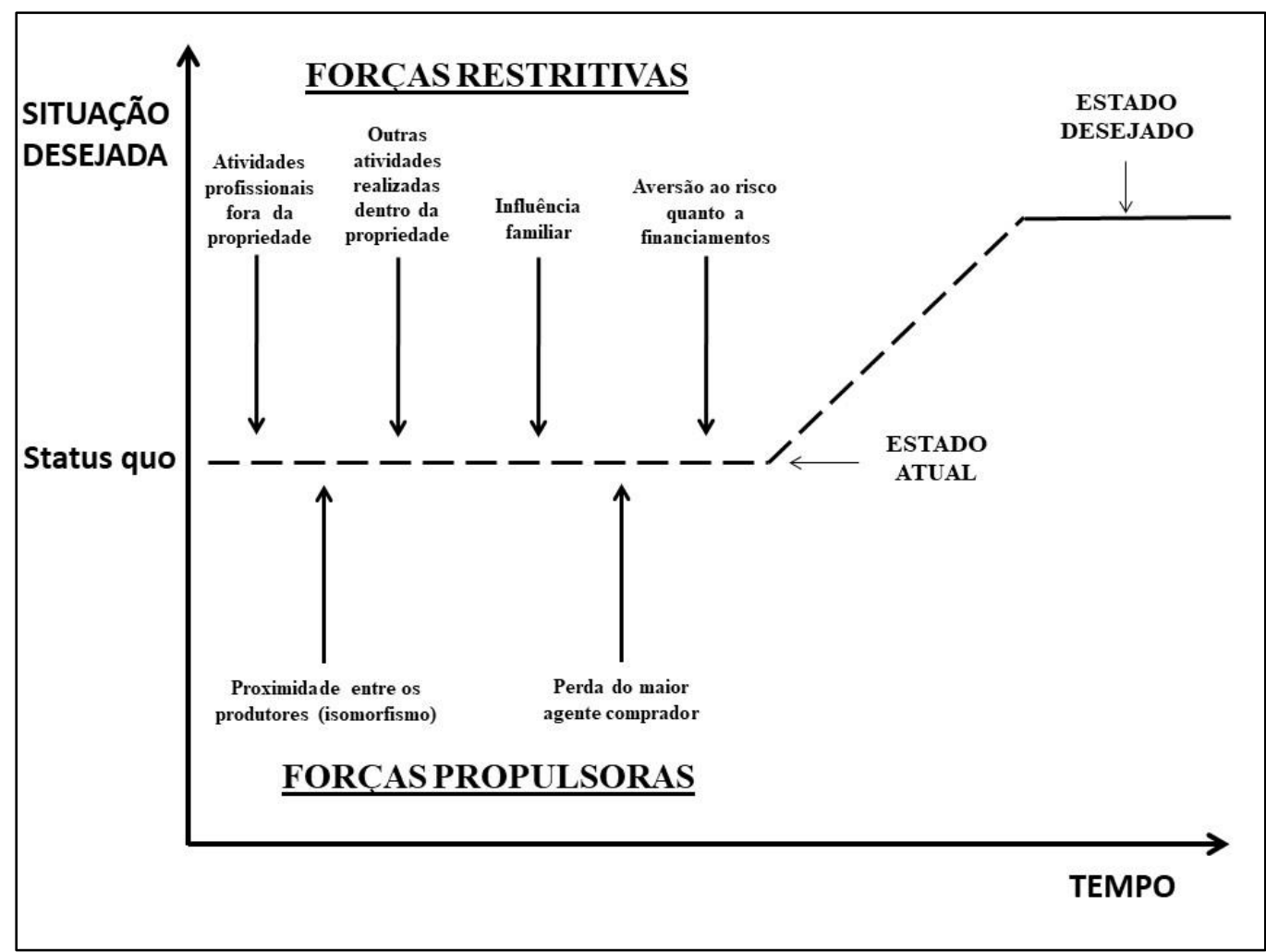

Figura 3. Forças restritivas e propulsoras para a adoção de inovações de uma comunidade de produtores de leite de búfalas de Queiroz/SP. Fonte: Adaptado de Robbins (2005).

\section{CONCLUSÕES}

A partir dos dados apresentados foi possível destacar a importância da produção de leite de búfala no município de Queiroz/SP, pois ela se apresenta representativa dentro do estado de São Paulo.

Com a pesquisa realizada verificouse que alguns produtores da comunidade analisada estão motivados a adotar inovações, tendo em vista que os mesmos necessitaram melhorar a qualidade do seu produto, por buscarem comercializá-lo com um laticínio da região do Vale do Ribeira/SP.

Apesar da motivação existente, muitos ainda possuem resistência à adoção de tecnologias na produção de leite de búfalas, seja pela aversão ao risco de financiamentos ou pela falta de foco, pois alguns estão desacreditados de seu negócio, por isso optam por realizarem outras atividades para a geração de renda. Além disto, foi identificado também que a influência familiar presente entre alguns destes produtores, os fazem dar continuidade em um negócio que talvez os mesmos não encarem como prioridade.

Pode-se concluir que a adoção de novas tecnologias é fundamental para a comunidade avaliada, a fim de que a mesma possa se manter no mercado. Porém, para que os produtores se fortaleçam para buscar esta tecnologia é extremamente importante que eles se unam de forma a exercer uma maior interatividade e, futuramente, filiem-se em alguma associação do setor a fim de buscarem novas ideias, estratégias e oportunidades de crescimento neste setor.

Para pesquisas futuras sugere-se analisar como a questão cultural e educacional influencia na adoção de inovações, no âmbito destes produtores, que permita a elaboração de um quadro amplo e interconectado sobre a necessidade de inovação desses produtores. 


\section{REFERÊNCIAS BIBLIOGRÁFICAS}

ANDRIGHETTO, C. Cadeia produtiva do leite de búfala: visão da universidade. In: SIMPÓSIO DA CADEIA PRODUTIVA DA BUBALINOCULTURA, 2., $2011 \mathrm{E}$ INTERNATIONAL SYMPOSIUM OF BUFFALO PRODUCTION CHAIN, 1., 2011, Botucatu. Anais... Botucatu: FEPAF, 2011.

ASSOCIAÇÃO BRASILEIRA DE CRIADORES DE BÚFALOS - ABCB. Regulamento Técnico do Programa do Selo de Pureza ABCB. 2014. Disponível em:

$<$ http://www.bufalo.com.br/regulamentodo selopureza.pdf>. Acesso em: 27 nov. 2017.

ASSOCIAÇÃO BRASILEIRA DE CRIADORES DE BÚFALOS - ABCB. Laticínio. Disponível em: <http://www.bufalo.com.br> Acesso em: 27 out. 2016.

BARTH, M.; RENNER, J. S.; NUNES, M. F.; SANFELICE, G. R. Características do trabalho na agricultura familiar e sua influência na emigração dos jovens. Iluminuras, Porto Alegre, v. 17 (41): 256276, 2016.

BERNARDES, O. Os Búfalos no Brasil. In: SIMPÓSIO DE BÚFALO DE LAS AMÉRICAS， 2., 2006 E SIMPÓSIO EUROPA-AMERICA, 2., 2006, Medellín. Anais... Medellín/Colombia: CD ROM, 2006.p.18-23.

BUAINAIN, A. M. Alguns condicionantes do novo padrão de acumulação da agricultura brasileira. In: BUAINAIN, A. $M$. et al. $O$ mundo rural no Brasil do século 21. Brasília: Embrapa, 2014, p. 211-240.

CIRANI, C. B. S.; MORAES, M. A. F. D. Inovação na indústria sucroalcooleira paulista: os determinantes da adoção das tecnologias de agricultura de precisão. RESR, Piracicaba, v. 48(4): 543-565, 2010.
CUNHA, S. K.; BOSZCKOWSKI, A. N.; FACCO, C. A. Ecologização do sistema setorial de inovação da soja no Brasil. Agroalimantaria, v. 17(32): 71-86, 2011.

DIMAGGIO, P. J.; POWELL, W. W. The iron cage revisited: institutional isomorphism and collective rationality in organizational fields. American Sociological Review, 1983.

GIL, A. C. Como elaborar projetos de pesquisa. 4. ed. São Paulo: Atlas, 2002.

GONÇALVES, O. Características de criações de búfalos no Brasil e a contribuição do marketing no agronegócio brasileiro. 2008. Tese (Doutorado) - Curso de Zootecnia, Faculdade de Zootecnia e Engenharia de Alimentos - Universidade de São Paulo, Pirassununga, 2008.

HAGE, J. T. Organizational innovation and organizational change. Annual Review of Sociology. v.25: 597-622, 1999.

INSTITUTO BRASILEIRO DE GEOGRAFIA E ESTATÍSTICA - IBGE. Produção da Pecuária Municipal 2015. Rio de Janeiro: IBGE, 2016. Disponível em

http://cidades.ibge.gov.br/xtras/home.php > Acesso em: 30 out. 2016.

LOPES, M. A. Informática aplicada à bovinocultura. Jaboticabal: FUNEP, 1997. 82p.

MARCONI, M. de A.; LAKATOS, E. M. Fundamentos de metodologia científica. 5. ed. São Paulo: Atlas, 2003.

MARTINS, V. Gestão da inovação em empresas que adotam diferentes processos de tomada de decisão. Revista Gestão \& Tecnologia, v. 15(3): 211-244, 2015. 
MINISTÉRIO DA AGRICULTURA PECUÁRIA E ABASTECIMENTO MAPA. Bovinos e Bubalinos. 2016. Disponível em: < http://www.agricultura.gov.br/animal/ especies/bovinos-e-bubalinos>. Acesso em: 31 out. 2016.

MINISTÉRIO DA AGRICULTURA PECUÁRIA E ABASTECIMENTO MAPA. SISBOV. 2017. Disponível em: $<$ http://sistemasweb.agricultura.gov.br/pag es/SISBOV.html>.

Acesso em: 06 dez. 2017.

NEUMANN, M. Processus d'idéation de référence pour la phase amont de l'innovation - Ideation Reference Process Model for the Early Phase of Innovation. 2013. 275 f. Tese (Doutorado) - Curso de Chemical And Process Engineering, L'université de Grenoble, Grenoble, 2013.

OECD. Guidelines for collecting and interpreting innovation data - Oslo Manual. $3^{\mathrm{a}}$ ed. 2005. Disponível em: < http://www.oecd-ilibrary.org/> Acesso em: 27 out. 2016

OLIVIERI, D. A. Avaliação da Qualidade Microbiológica de Amostras de Mercado de Queijo Mussarela, elaborado a partir de leite de búfala (Bubalis bubalis). 2004. 61 p. Dissertação (Mestrado) - USP - ESALQ, Piracicaba, 2004.

ROBBINS, S. P. Comportamento Organizacional. São Paulo: Pearson Prentice Hall, 2005.

ROGERS, E. M. Diffusion of innovations. $3^{\mathrm{a}}$ ed. New York: The Free Press, 1983.

ROVER, O. J. Agroecologia, mercado e inovação social: o caso da rede Ecovida de
Agroecologia. Ciências Sociais Unisinos, v. 47(1): 56-63, 2011.

SANTINI, G. A.; BERNARDES, O.; SCARPELLI, J. U. Análise das relações comerciais do segmento de processamento de leite e derivados de leite de búfala no estado de São Paulo. Informações Econômicas, v. 43(5): 69-84, 2013.

SCHUMPETER, J. A. (1943) O processo de destruição criadora. In:

Capitalismo, socialismo e democracia. Rio de Janeiro: Zahar, 1984.

SOUZA FILHO, H. M. et al. Condicionantes da adoção de inovações tecnológicas na agricultura. Cadernos de Ciência \& Tecnologia, v. 28(1): 223-255, 2011.

STURARO, M. J. R. Avaliação socioeconômica e de qualidade na produção do leite bubalino no município de Sarapuí - SP. 2014. Dissertação (Mestrado) - Curso de Sanidade, Segurança Alimentar e Ambiental no Agronegócio, Instituto Biológico, São Paulo, 2014.

TEIXEIRA, L. V.; et al. Leite de Búfala na Indústria de Produtos Lácteos. Revista Brasileira de Reprodução Animal, Belo Horizonte, MG, v. 29 (2): 96-100, 2005.

VELOSO JUNIOR, F. A. Cadeia produtiva da bubalinocultura: visão do produtor. In: SIMPÓSIO DA CADEIA PRODUTIVA DA BUBALINOCULTURA, 2., 2011 E INTERNATIONAL SYMPOSIUM OF BUFFALO PRODUCTION CHAIN, 1., 2011, Botucatu. Anais... Botucatu: CEPLAC, 2011.

VERTEL, A. C. C.; PATERNINA, C. D. R.; RIAÑO, H. E. H.; PEREIRA, J. M. L. Cultura organizacional: evolución en la medición. Revista Estudos Gerenciales, v. 29(128): 350-355, 2013. 